\title{
Fruit and Vegetable Peels: Utilization of High Value Horticultural Waste in Novel Industrial Applications
}

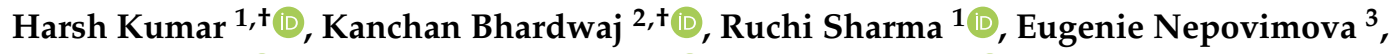 \\ Kamil Kuča ${ }^{3, * \mathbb{D}}$, Daljeet Singh Dhanjal ${ }^{4}$ (D), Rachna Verma ${ }^{2} \mathbb{D}$, Prerna Bhardwaj ${ }^{2}$, \\ Somesh Sharma ${ }^{1}$ and Dinesh Kumar ${ }^{1, *(1)}$ \\ 1 School of Bioengineering \& Food Technology, Shoolini University of Biotechnology and Management \\ Sciences, Solan-173229, India; microharshs@gmail.com (H.K.); mails4sharmaruchi@gmail.com (R.S.); \\ someshsharma@shooliniuniversity.com (S.S.) \\ 2 School of Biological and Environmental Sciences, Shoolini University of Biotechnology and Management \\ Sciences, Solan-173229, India; kanchankannu1992@gmail.com (K.B.); \\ rachnaverma@shooliniuniversity.com (R.V.); prernabhardwaj135@gmail.com (P.B.) \\ 3 Department of Chemistry, Faculty of Science, University of Hradec Kralove, \\ 50003 Hradec Kralove, Czech Republic; eugenie.nepovimova@uhk.cz \\ 4 School of Biotechnology and Biosciences, Lovely Professional University, Phagwara-144411, Punjab, India; \\ daljeetdhanja192@gmail.com \\ * Correspondence: kamil.kuca@uhk.cz or kamil.kuca@fnhk.cz (K.K.); \\ dineshkumar@shooliniuniversity.com (D.K.); Tel.: +420-603-289-166 (K.K.) \\ + These authors share the first authorship.
}

Received: 23 May 2020; Accepted: 16 June 2020; Published: 18 June 2020

check for updates

\begin{abstract}
Fruits and vegetables are the highly used food products amongst the horticultural crops. These items are consumed uncooked, nominally cooked or fully cooked, according to their nature and cooking process. With the change in diet habits and rising population, the production, as well as the processing of horticultural crops, has exponentially improved to meet its increasing demand. A large amount of peel waste is generated from fruit and vegetable-based industries and household kitchen and has led to a big nutritional and economic loss and environmental problems. Processing of fruits and vegetables alone generates a significant waste, which amounts to $25-30 \%$ of the total product. Most common wastes include pomace, peels, rind and seeds, which are highly rich in valuable bioactive compounds such as carotenoids, enzymes, polyphenols, oils, vitamins and many other compounds. These bioactive compounds show their application in various industries such as food to develop edible films, food industries for probiotics and other industries for valuable products. The utilization of these low-cost waste horticultural wastes for producing the value-added product is a novel step in its sustainable utilization. The present review intends to summarize the different types of waste originating from fruits as well as vegetables peels and highlight their potential in developing edible films, probiotics, nanoparticles, carbon dots, microbial media, biochar and biosorbents.
\end{abstract}

Keywords: fruits; vegetables; peels; edible films/coatings; probiotics; nanoparticles; carbon dots; microbiological media; biochar; biosorbents 


\section{Introduction}

In the European Union, approximately 89 million tons of food waste is generated, and this value is expected to increase by 40 -fold in coming years. The Food and Agriculture Organization (FAO) estimated that around $40 \%$ of the food produced in India is wasted [1,2]. Moreover, the Food Corporation of India reported this loss ranging between 10 to 15 percent of the total production. The Ministry of Food Processing Industries (MFPI) India estimated fruit and vegetable losses to be 12 and 21 million tons, respectively, amounting to an approximate value of about 4.4 billion USD, with a total food value loss and waste produce of 10.6 billion USD [2]. A broader term is "fruit and vegetable waste" (FVW), which refers to indigestible parts that are thrown away at different stages such as collection, handling, shipping and processing [3]. In accordance with the above definition, FVW can be considered as fruit and vegetable loss instead of waste. FVW can be produced at different steps from farm to consumer, involving both pre- and post-consumer stages of the food supply chain [4].

There are high amounts of phytochemical constituents present in FVW and studied for dietary fibers, phenolic compounds and other bioactive compounds extraction [5]. Studies revealed that essential nutrients and phytochemicals are abundantly found in the peels, seeds and other constituent of vegetables and fruits in common use [6]. For instance, the skin of avocados, grapes, lemons, seeds of jackfruits and mangoes contains $15 \%$ higher phenolic concentrations as compared to fruit pulp $[7,8]$. The FVWs can be utilized to extract as well as obtain bioactive compounds that can be used in cosmetics, food, textile and pharmaceutical industries as shown in Figure 1. Some of the FVWs waste originates from horticultural supplies, which is not considered important at present. Their proper use will not only solve the environmental issues, but will act as a sustainable approach to improve health via enriched food containing health-enhancing substances [9]. The current review summarizes the scientific inventions and reviews the recent advances in the exploitation of waste fruits and vegetables peel as a valuable commodity of the future.

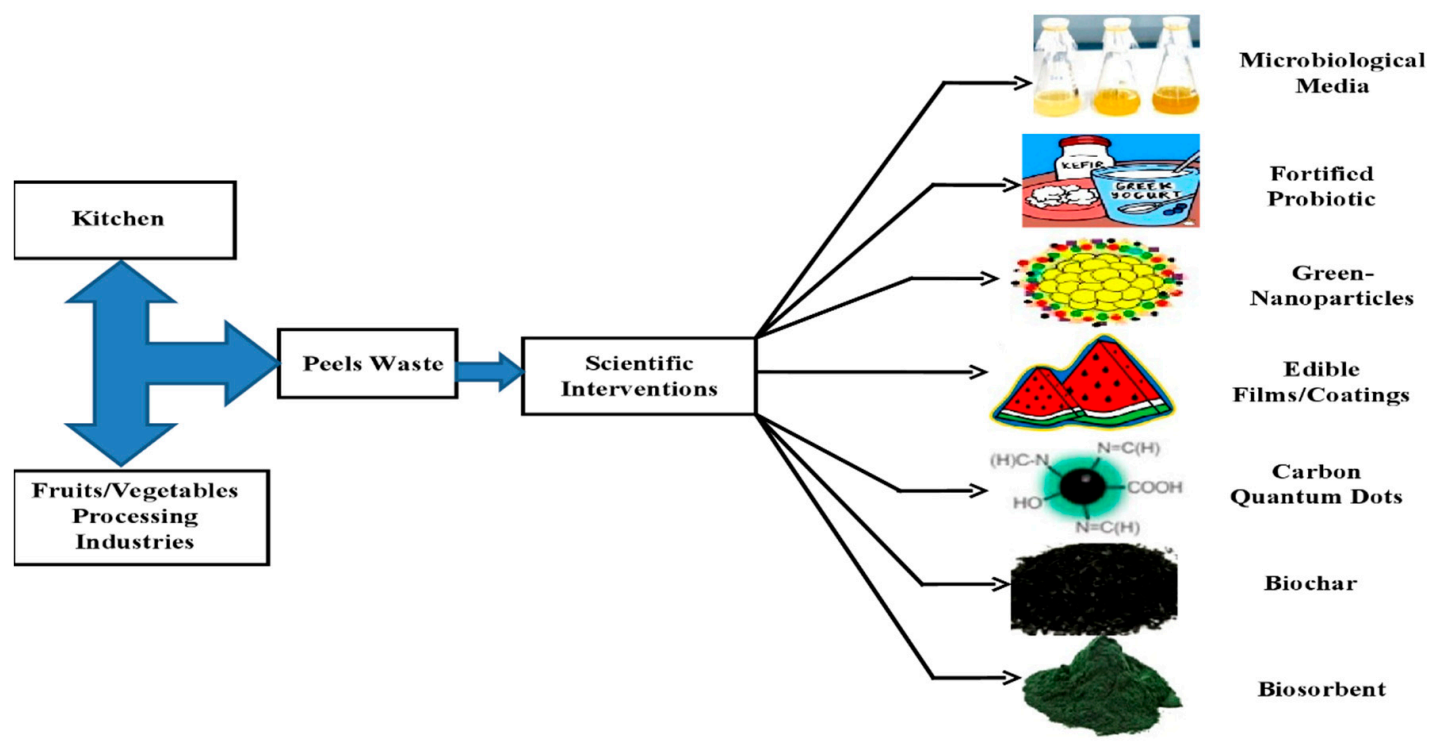

Figure 1. Utilization of fruits and vegetable peel-based waste into novel industrial products [10-16]. 


\section{Fruit and Vegetable Peel Based Edible Coatings/Films}

Edible coatings are made up of thin layers applied on the surface of the food to make its shelf life longer, maintain the properties, characteristics and functionality of foods at minimum cost [17]. This application can increase its functionality by extending the shelf life, preventing the microbial spoilage and acting as a carrier matrix for antimicrobial agents $[18,19]$. Coating can be considered as an effective method of preservation during transport of fruits and vegetables easily affected by microorganisms, insects, pre- and post-harvesting conditions [20]. Coatings also help in developing a modified atmosphere to induce varied alterations in minimally processed and fresh foodstuff in various areas such as sensory quality, antioxidant properties, color, firmness, ethylene production, microbial growth inhibition and organic compounds under anaerobic processes [21]. Recently, essential oils (EOs) and their main components have received substantial attention due to the presence of effective antimicrobial properties in them. The main EO component of lemongrass citral (3,7-dimethyl-2,6-octadienal) has been reported for its antimicrobial activity against a variety of foodborne pathogens and is also explored as an antimicrobial agent in edible coatings [22]. The EOs are commonly considered as safe, as they impart maximum effects with the minimum change in the organoleptic properties of the food [23]. Of late, in the development of edible coatings applications of this emerging technology included a variety of nanosystems, consisting of nanoemulsions, polymeric nanoparticles and nanocomposites to release antioxidants, and showing antibacterial activities on the surface of the food. Because of the many phenolic substances with excellent antioxidant capacity, fruits and vegetable peel are considered as suitable materials for inclusion into films and coatings.

Fish gelatin is believed to be a valuable biopolymer source for fabricating biofilms because of its biodegradable nature and high myofibrillar protein content [24]. Additionally, because of the variations in the sequence of amino acid, fruit and vegetable peel-based films show less water permeability in contrast to mammalian gelatin-based film. Enriching pomegranate peel powder in gelatin films considerably increased their water vapor permeability (WVP) as incomplete dissolution of pomegranate peel in the film matrix resulted in more heterogeneous microstructure [25]. Both hydrophobic and hydrophilic components present in the peel of pomegranate balances the hygroscopic properties and do not alter the moisture content of the films (Table 1). 
Table 1. Fruits and vegetables peel based edible films/coating with their applications.

\begin{tabular}{|c|c|c|c|c|c|c|}
\hline $\begin{array}{l}\text { Fruit/Vegetable } \\
\text { Common Name }\end{array}$ & Scientific Name & Matrix & Applied on Food Items & Technique Used & Beneficial Effects & Ref \\
\hline Apple & Malus domestica & Carboxy methylcellulose & Fresh beef patties & Microfluidization & $\begin{array}{l}\text { A complete inhibition of lipid oxidation, and efficient } \\
\text { suppression of the growth of microbes on raw beef } \\
\text { patties. No effect on the sensory characteristics of raw } \\
\text { and cooked beef patties }\end{array}$ & [26] \\
\hline Orange & Citrus sinensis & Gelatin & Cupcake & ND & $\begin{array}{c}\text { Increase in peroxide value by } 3.60-4.80 \text { (mL.eq./kg fat) } \\
\text { in refrigerated storage for } 1 \text { week and decrease in } \\
\text { microbial growth }\end{array}$ & {$[27]$} \\
\hline Pomegranate & Punica granatum & Mung bean protein & NS & ND & $\begin{array}{l}\text { The films enriched with pomegranate peel also showed } \\
\text { higher total phenolic content; antioxidant activity, } \\
\text { antibacterial capacity compared to the control mung } \\
\text { bean protein film. These films found their use in food } \\
\text { industry to develop bio-functional edible films } \\
\text { intended for packaging of food products }\end{array}$ & [28] \\
\hline Potato & Solanum tuberosum & Oregano essential oil (OEO) & Cold-smoked salmon & ND & $\begin{array}{c}\text { When samples were coated with Potato processing } \\
\text { waste-based-oregano oil-incorporating film (PPW-OO), } \\
\text { the Listeria population decreased from } 6.7 \text { to } 4.7 \mathrm{log} \\
\text { CFU/g by the end of storage. Incorporation of oil into } \\
\text { the films reduced the film strength and increased their } \\
\text { water vapor permeability. The PPW-OO film reduced } \\
\text { the growth of Listeria monocytogenes on cold-smoked } \\
\text { salmon during storage under vacuum conditions at } \\
4^{\circ} \mathrm{C} \text { for } 28 \text { days }\end{array}$ & [29] \\
\hline Orange & $\begin{array}{l}\text { Citrus sinensis (L.) } \\
\text { Osbeck }\end{array}$ & Chitosan film & Deepwater pink shrimp & Casting & $\begin{array}{l}\text { The combination of chitosan film with } 2 \% \text { orange peel } \\
\text { essential oil concentration was effective in prolonging } \\
\text { the shelf life of fresh shrimps to } 15 \text { days }\end{array}$ & [30] \\
\hline Orange & $\begin{array}{l}\text { Citrus sinensis (L.) } \\
\text { Osbeck }\end{array}$ & Gelatin & Shrimps & ND & $\begin{array}{l}\text { Gelatin coating combined with orange peel essential oil } \\
\text { preserved shrimp quality during cold storage with a } \\
\text { shelf-life extension of about } 6 \text { days }\end{array}$ & [23] \\
\hline
\end{tabular}


Table 1. Cont

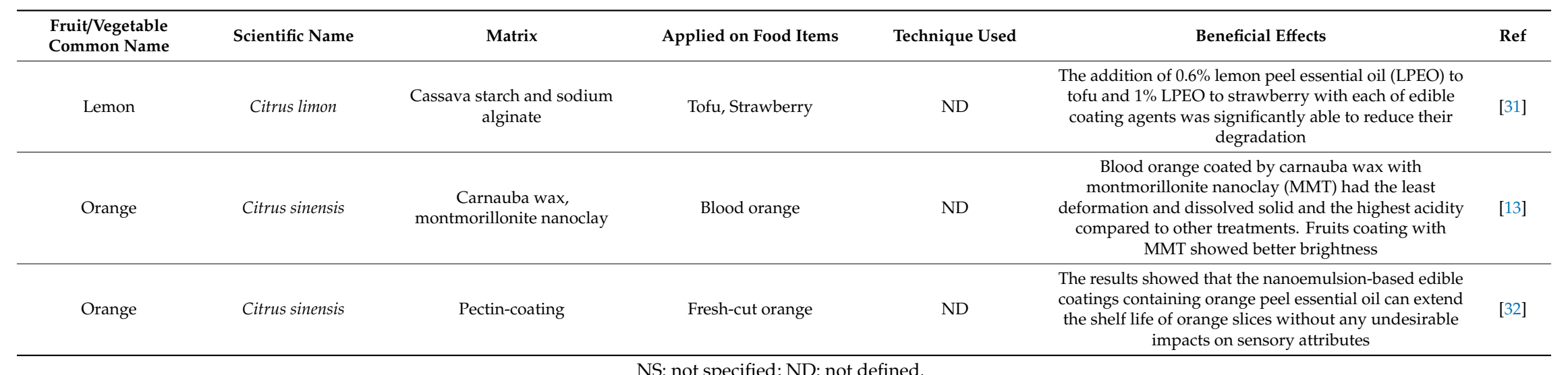

NS: not specified; ND: not defined. 
The peel of potato contains adequate quantities of cellulose, fermentable sugars, hemicellulose, and starch [33]. The films with low concentration peel of potato after comparison with high concentrations peel in the biopolymer film resulted in a higher WVP due to bigger pore size of film matrix despite its denser structure [33]. Potato peel biopolymer film-coating proved helpful for designing biodegradable food packaging with more-value commercial use. Generally, fish gelatin/polyethylene bilayer films solubility was lowered by enriching with different fruit peels [34].

\section{Fruit and Vegetable Peel Fortified Probiotics}

Over the past two centuries, fruits have been used as a remedy for dry cough, severe thirst and sore throat in medicine. In the last few years, the demand for novel functional foods has increased and probiotics are commonly consumed all over the world and considered as one of the main functional food products [35]. Additionally, the fruits and peels are of great value and high source of bioactive compounds. In pomegranate, citrus, mango and Opuntia ficus-indica (barbary fig) peel, the functional ingredients present in abundance are antioxidants, fiber and oligosaccharides (as prebiotics) [36-39]. Probiotics and dietary fiber both have been reported to reduce the incidence of colon cancer and relieve constipation [40]. Additionally, some dietetic fibers obtained from fruits have shown considerable effect on the viability of these bacteria and are recommended as an ingredient in probiotic dairy foods [11]. Various attempts have been made to increase the biological activities of probiotics, including supplementation with fruit peel.

Probiotic yogurt prepared with pineapple peel powder improved the anticancer, antioxidant and antibacterial activities against Escherichia coli, but no significant effect was observed on Staphylococcus aureus [41]. The addition of apple, banana and passion fruit peel powder in probiotic yogurt improved the rheological properties and enhanced the growth of Lactobacillus casei, Bifidobacterium animalis subsp. lactis, Lactobacillus acidophilus and Lactobacillus paracasei [11]. The effect of milk supplementation with mango peels on the kefir microorganism's growth rates and antioxidant properties were also estimated in fermented products [42]. Composite fruit peel powder (orange, passion fruit and pineapple) was used in different proportions i.e., $1 \%, 0.5 \%$ and $0.7 \%(w / v)$, respectively, to develop fat and sugar-free probiotic set yogurt [43]. Increase in firmness and consumer acceptability, decrease in syneresis and high lactic acid bacteria counts were observed in yogurt incorporated with $0.5 \%$ peel mixtures.

\section{Fruit and Vegetable Peel-Derived Metallic Nanoparticles}

Beneficial bioactive molecules such as alkaloids, amino acids, enzymes, phenolics, proteins, polysaccharides, tannins, saponins, vitamins and terpenoids and other compounds present in fruits and vegetable waste generally act as reducing agents in metal nanoparticles (NPs) synthesis [44,45]. Some biomolecules play the role of modeling agents directing particle growth in a specific direction, while other biomolecules function as capping agents, preventing nanoparticle from getting agglomerated [46,47]. Nanoparticles biosynthesized by using FVW have also emerged as a reliable, sustainable and eco-friendly technology with lower risk to human health and environmental as compared with chemicals and toxic solvents based conventional manufacturing protocol [48]. A significant interest in use of NPs was reported due to their distinctive physicochemical properties and applications in various fields of biomedicine and pharmaceuticals. The biogenic NPs are synthesized by following the bottom-up approach, in which atoms as well as compounds act as the building block and self-assembled themselves to form the final product $[49,50]$.

Various noble metal/metal oxide NPs have been synthesized from fruits and vegetables peel extracts as shown in Table 2. 
Table 2. Fruits and vegetables peel derived metallic nanoparticles with their application.

\begin{tabular}{|c|c|c|c|c|c|c|c|}
\hline $\begin{array}{l}\text { Fruit/Vegetable } \\
\text { Common Name }\end{array}$ & Scientific Name & $\begin{array}{c}\text { Types of } \\
\text { Nanoparticles } \\
\text { Synthesized }\end{array}$ & Reaction Time & Morphology & Size & Applications & Ref \\
\hline $\begin{array}{l}\text { Pomegranate; } \\
\text { Orange; Banana } \\
\text { and Apple }\end{array}$ & $\begin{array}{l}\text { Punica granatum; Citrus } \\
\text { sinensis; Musa; Malus } \\
\text { domestica }\end{array}$ & Silver & $2 \mathrm{~min}$ & Sphere & $25 \mathrm{~nm}$ & $\begin{array}{c}\text { Antibacterial activity against Salmonella sp., } \\
\text { Escherichia coli, Pseudomonas sp., Aeromonas } \\
\text { hydrophila; Antifungal activity against Fuarium sp.; } \\
\text { Antioxidant activity using } \\
\text { 2,2-diphenyl-1-picrylhydrazyl (DPPH); Cytotoxicity } \\
\text { against human breast cancer cells MCF-7 }\end{array}$ & [51] \\
\hline Orange; Banana & Citrus sinensis; Musa & Silver & $1 \mathrm{~h}$ & Sphere & ND & $\begin{array}{c}\text { Antibacterial activity against Staphylococcus aureus, } \\
\text { Proteus vulgaris }\end{array}$ & [52] \\
\hline $\begin{array}{l}\text { Orange; Lemon; } \\
\text { Sweet lemon }\end{array}$ & $\begin{array}{l}\text { Citrus sinensis; Citrus } \\
\text { limon; Citrus limetta }\end{array}$ & Silver & $24 \mathrm{~h}$ & ND & ND & $\begin{array}{l}\text { Antibacterial activity against Pseudomonas } \\
\text { aeruginosa, E. coli and Salmonella typhimurium }\end{array}$ & [53] \\
\hline Orange & Citrus sinensis & Silver & $10 \mathrm{~min}$ & Sphere & $47-53 \mathrm{~nm}$ & Photocatalytic against methylene blue & [54] \\
\hline Lemon & Citrus limon & Silver & $30 \mathrm{~min}$ & Sphere & $2-5 \mathrm{~nm}$ & $\begin{array}{l}\text { Antibacterial activity against } P \text {. aeruginosa, E. coli, } \\
\text { Acinetobacter baumannii, Streptococcus mutans, Proteus } \\
\text { mirabilis; Antifungal activity against Candida albicans }\end{array}$ & [55] \\
\hline Pomegranate & Punica granatum & Silver & $24 \mathrm{~h}$ & ND & $5-50 \mathrm{~nm}$ & $\begin{array}{c}\text { Antibacterial activity against } \text { S. aureus, P. aeruginosa, } \\
\text { E. coli }\end{array}$ & [12] \\
\hline Banana & Musa paradisiaca & Silver & $1 \mathrm{~h}$ & Sphere & $23.7 \mathrm{~nm}$ & $\begin{array}{c}\text { Antibacterial activity against } P \text {. aeruginosa, E. coli, } S \text {. } \\
\text { aureus, Bacillus subtilis; Antifungal activity against } C \text {. } \\
\text { albicans }\end{array}$ & [56] \\
\hline Pomegranate & Punica granatum & Silver & $24 \mathrm{~h}$ & Sphere & $20-40 \mathrm{~nm}$ & $\begin{array}{c}\text { Antibacterial activity against } E \text {. coli, } P \text {. vulgaris, } P \text {. } \\
\text { aeruginosa, S. typhimurium, } \text { S. aureus, Staphylococcus } \\
\text { epidermidis, Klebsiella pneumonia; } \text { Cytotoxicity against } \\
\text { human colon cancer cell line RKO: ATCC }{ }^{\circledR} \\
\text { CRL-2577'TM }\end{array}$ & [57] \\
\hline Apricot & Prunusa rmeniaca & Silver & NS & Rod & $50 \mathrm{~nm}$ & $\begin{array}{c}\text { Antibacterial activity against } E \text {. coli, S. aureus, } P \text {. } \\
\text { aeruginosa, B. subtilis }\end{array}$ & [58] \\
\hline Cavendish banana & Musa acuminata & Silver & $30 \mathrm{~min}$ & Sphere & $55 \mathrm{~nm}$ & $\begin{array}{l}\text { Antibacterial activity against S. aureus, B. subtilis, E. } \\
\text { coli, K. pneumonia; Antioxidant activity (DPPH), } \\
\text { 2,2'-azino-bis(3-ethylbenzothiazoline-6-sulfonic } \\
\text { acid) (ABTS) }\end{array}$ & [59] \\
\hline
\end{tabular}


Table 2. Cont

\begin{tabular}{|c|c|c|c|c|c|c|c|}
\hline $\begin{array}{l}\text { Fruit/Vegetable } \\
\text { Common Name }\end{array}$ & Scientific Name & $\begin{array}{l}\text { Types of } \\
\text { Nanoparticles } \\
\text { Synthesized }\end{array}$ & Reaction Time & Morphology & Size & Applications & Ref \\
\hline Orange & Citrus sinensis & Silver & $5 \mathrm{~h}$ & ND & $48.1 \mathrm{~nm}$ & $\begin{array}{l}\text { Antibacterial activity against Xanthomonas } \\
\text { axonopodis pv. citri (Xac) }\end{array}$ & [60] \\
\hline $\begin{array}{l}\text { Tomato; Orange; } \\
\text { Grapefruit; Lemon }\end{array}$ & $\begin{array}{l}\text { Lycopersicon esculentum; } \\
\text { Citrus sinensis; Citrus } \\
\text { Paradise; Citrus } \\
\quad \text { aurantifolia }\end{array}$ & Zinc Oxide & $1 \mathrm{~h}$ & Hexagonal & $\begin{array}{l}9.01 \mathrm{~nm} ; 12.55 \mathrm{~nm} ; \\
19.66 \mathrm{~nm} ; 11.39 \mathrm{~nm}\end{array}$ & Photocatalytic against methylene blue & [61] \\
\hline Sweet Potato & $\begin{array}{l}\text { Ipomoea batatas }(\mathrm{L} .) \\
\quad \text { Lam.(Ib) }\end{array}$ & Silver & $1-12 \mathrm{~h}$ & Agglomerated & ND & $\begin{array}{l}\text { Antibacterial activity against Enterococcus feacium, } \\
\text { Salmonella enteritica, Listeria monocytogenes, B. cereus, } \\
\text { S. aureus; Antidiabetic; Antioxidant activity (DPPH, } \\
\text { ABTS, nitrite/nitrate oxide (NOx)); Cytotoxicity } \\
\text { against HepG2 cancer cells }\end{array}$ & [62] \\
\hline Potato & Solanum tuberosum & Zinc Oxide & $24 \mathrm{~h}$ & Hexagonal & $30-150 \mathrm{~nm}$ & Photocatalytic against methylene blue and azo dyes & [63] \\
\hline Onion & Allium сера & Gold & $24 \mathrm{~h}$ & $\begin{array}{l}\text { Sphere and } \\
\text { Triangle }\end{array}$ & $45.42 \mathrm{~nm}$ & $\begin{array}{l}\text { Synergistic antimicrobial potential against } B \text {. cereus, } \\
\text { E. coli, L. monocytogenes, S. aureus, S. typhimurium; } \\
\text { Antifungal activity against } C \text {. albicans, C. glabrata, C. } \\
\text { glochares; Antioxidant activity (DPPH, ABTS, NOx) }\end{array}$ & [64] \\
\hline Bottle gourd & Lagenaria siceraria & Silver & $20 \mathrm{~h}$ & Sphere & $5-40 \mathrm{~nm}$ & $\begin{array}{c}\text { Cytotoxicity against A431, (skin carcinoma, p53 } \\
\text { mutant) and A549, (lung carcinoma, p53 wild type); } \\
\text { Antibacterial activity against S. typhi }\end{array}$ & [65] \\
\hline Radish & Raphanus sativus & Silver & $15 \mathrm{~min}$ & Polygonal & $30-60 \mathrm{~nm}$ & $\begin{array}{l}\text { Antibacterial activity against } S \text {. aureus, B. subtilis, E. } \\
\text { coli, K. pneumonia }\end{array}$ & [66] \\
\hline
\end{tabular}

NS: not specified; ND: not defined. 
Gold ( $\mathrm{Au}$ ) NPs have been synthesized using dried onion peels (OP) aqueous extract, which reduces $\mathrm{Au}^{3+}$ to OP-AuNPs by forming a colloidal solution [64]. The phytoconstituents, mainly the cysteine derivatives, found in the onion bulb, might be responsible for the synthesis of OP-AuNPs. Zinc oxide $(\mathrm{ZnO})$ nanoparticles were synthesized with domestic waste potato peel after $24 \mathrm{~h}$ of incubation using starch present in the potato peel to reduce the metal ion [63]. Banana, pomegranate, lemon and orange peel extracts have also been found to possess the ability to reduce silver $\left(\mathrm{Ag}^{+}\right)$ions in aqueous solutions to synthesize silver (Ag) nanoparticles [54-57]. Likewise, ZnO-NPs have been synthesized using tomato, grapefruit, lemon and orange peel [61].

\section{Fruit and Vegetable Peel Derived Carbon Dots}

Carbon dots (CDs) are a very small $(<10 \mathrm{~nm})$ photoluminescent material synthesized by two approaches, i.e., top-down and bottom-up synthetic routes $[67,68]$. In the top-down synthetic route, a large carbon structure breaks down by involving acid assisted chemical oxidation, electro-oxidation or laser ablation in the synthesis process [69]. However, this approach requires a complex and extreme synthetic condition, which is considered as one of the disadvantages of this method. On the other hand, the bottom-up approach using plants and their byproducts without using chemicals was found advantageous over the top-down approach. Food waste is a matter of serious concern worldwide, and this waste needs to be given proper attention. The use of food as waste offer economic benefits and is one of the most interesting starting materials as carbon sources for the synthesis of CDs [67]. Presence of functional components such as carotenoids, dietary fiber, gallic acid, polyphenols, flavonoids and mangiferin in mango peel and pineapple peel makes these suitable for the development of CDs $[70,71]$. The increasing number of publications shows that the fruit and vegetable by-products are source of antibacterial, antioxidant and nutritional dietary fiber [72]. Additionally, because of their biocompatibility, innocuousness, low toxicity, low cost and photostability properties, they are suitable starting materials for CDs $[73,74]$. The appropriate properties, i.e., pyrolyzation at high temperature and oxygenolysis with concentrated acid, carbonization, oxidation, polymerization and nucleation are needed during peels treatment to synthesize CDs [14]. CDs have shown a promising potential for applications in biomedical to energy storage devices, determination of pathogens, environmental studies, detection of heavy metals and additives in the food and water purification processes (Table 3) [75,76].

Table 3. Fruits and vegetables peel as a carbon source for preparing carbon dots.

\begin{tabular}{|c|c|c|c|c|c|}
\hline $\begin{array}{l}\text { Fruits/Vegetable } \\
\text { Common Name }\end{array}$ & $\begin{array}{l}\text { Scientific } \\
\text { Name }\end{array}$ & Production Conditions & $\begin{array}{c}\text { Detection Limit of } \\
\text { Heavy Metals }\end{array}$ & Applications & Ref \\
\hline Mango & Mangifera indica & Hydrothermal $/ 300^{\circ} \mathrm{C} / 2 \mathrm{~h}$ & $1.2 \mu \mathrm{M}$ & $\begin{array}{l}\text { Cellular labeling ferrous } \\
\text { ion }\left(\mathrm{Fe}^{2+}\right) \text { detection }\end{array}$ & {$[14]$} \\
\hline Pineapple & Ananas comosus & Hydrothermal $/ 200^{\circ} \mathrm{C} / 3 \mathrm{~h}$ & $4.5 \mathrm{nM}$ & $\begin{array}{c}\text { Electronic security } \\
\text { devices mercury ion } \\
\left(\mathrm{Hg}^{2+}\right) \text { quantification }\end{array}$ & [77] \\
\hline Lemon & Citrus limon (L.) & Hydrothermal $/ 200^{\circ} \mathrm{C} / 8 \mathrm{~h}$ & $73 \mathrm{nM}$ & $\begin{array}{c}\mathrm{Cr}^{6+} \text { sensing; } \\
\text { Photocatalysis effect }\end{array}$ & [75] \\
\hline Sweet lemon & Citrus limetta & Hydrothermal $/ 180^{\circ} \mathrm{C} / 3 \mathrm{~h}$ & NA & $\begin{array}{l}\text { Breast cancer detection } \\
\text { gene therapy }\end{array}$ & [78] \\
\hline Banana & Musa acuminata & $\begin{array}{c}\text { Microwave-assisted/500 } \\
\text { W/20 min }\end{array}$ & NA & $\begin{array}{l}\text { Determination of } \\
\text { colitoxin DNA }\end{array}$ & [79] \\
\hline Pomelo & Citrus maxima & Hydrothermal $/ 200^{\circ} \mathrm{C} / 3 \mathrm{~h}$ & $0.23 \mathrm{nM}$ & $\mathrm{Hg}^{2+}$ sensing & [80] \\
\hline Grapefruit & Citrus paradisi & Hydrothermal/190 ${ }^{\circ} \mathrm{C} / 12 \mathrm{~h}$ & NA & $\begin{array}{c}\text { Photoluminescence } \\
\text { immunoassay }\end{array}$ & [81] \\
\hline Onion & Allium cepa & $\begin{array}{l}\text { Microwave-assisted/1000 } \\
\text { W/a specific time intervals }\end{array}$ & NA & $\begin{array}{l}\text { Skin wound healing; } \\
\text { Living cells imaging }\end{array}$ & [82] \\
\hline
\end{tabular}


Table 3. Cont

\begin{tabular}{|c|c|c|c|c|c|}
\hline $\begin{array}{l}\text { Fruits/Vegetable } \\
\text { Common Name }\end{array}$ & $\begin{array}{l}\text { Scientific } \\
\text { Name }\end{array}$ & Production Conditions & $\begin{array}{l}\text { Detection Limit of } \\
\text { Heavy Metals }\end{array}$ & Applications & Ref \\
\hline Watermelon & Citrullus lanatus & Hydrothermal $/ 220^{\circ} \mathrm{C} / 2 \mathrm{~h}$ & NA & Imaging probe & [83] \\
\hline Citrus & $\begin{array}{l}\text { Citrus sinensis, } \\
\text { Citrus limon }\end{array}$ & Hydrothermal $/ 180^{\circ} \mathrm{C} / 2 \mathrm{~h}$ & $0.01 \mu \mathrm{M}$ & $\begin{array}{l}\text { Ferric ion }\left(\mathrm{Fe}^{3+}\right) \text { and } \\
\text { tartrazine sensing; Cell } \\
\text { imaging }\end{array}$ & [84] \\
\hline Orange & Citrus sinensis & Hydrothermal $/ 150^{\circ} \mathrm{C} / 10 \mathrm{~h}$ & NA & Photocatalytic activity & [85] \\
\hline Mangosteen & $\begin{array}{c}\text { Garcinia } \\
\text { mangostana }\end{array}$ & $\begin{array}{l}\text { Hydrothermal } / 200^{\circ} \mathrm{C} / 30 \\
\min \end{array}$ & NA & Cells imaging & [86] \\
\hline Pomegranate & $\begin{array}{l}\text { Punica } \\
\text { granatum }\end{array}$ & Hydrothermal $/ 180^{\circ} \mathrm{C} / 36 \mathrm{~h}$ & NA & Recovery of latent prints & [87] \\
\hline Banana & Musa acuminata & Hydrothermal $/ 200^{\circ} \mathrm{C} / 2 \mathrm{~h}$ & $211 \mathrm{nM}$ & $\begin{array}{l}\text { Selective and sensitive } \\
\text { detection of } \mathrm{Fe}^{3+} \text { ions }\end{array}$ & [88] \\
\hline
\end{tabular}

NA-not applicable.

\section{Fruit and Vegetable Peel Based Microbiological Media}

In microbiological studies, microorganisms are grown by adding suitable culture media with favorable environment under laboratory conditions [89]. In most of the cases, commercially available media such as Cetrimide agar, Nutrient agar and MacConkey agar are used, but these are generally considered high cost media [89]. The growth and isolation of organisms have been reported using different substrates and media [90]. Some fruits and vegetables, such as cabbage, carrot, gooseberry, tomato, pumpkin etc., have been used as a substitute for nutrient agar to culture both bacteria and fungi, [91]. Other reports have used black gram, cowpea and green gram as starch and protein substitutes to ease the microbial media cost [92]. Fruits and vegetable bio-waste contain simple and complex sugars that are metabolized by microorganisms and have received much attention for their use in animal feed, bio-ethanol and biogas production [93,94].

Different type of agriculture waste is now used for the production of low-cost growth media for microorganisms (Table 4) [95,96].

Table 4. Fruits and vegetables peel based microbiological media.

\begin{tabular}{|c|c|c|c|c|}
\hline $\begin{array}{l}\text { Fruit/Vegetable } \\
\text { Common Name }\end{array}$ & Scientific Name & Medium Composition & Purpose/Utilization & Ref \\
\hline Dragon fruit & Hylocereus undatus & $\begin{array}{l}\text { Dragon fruit peel powder }(33.3 \\
\mathrm{g} / \mathrm{L}) \text {, peptone }(20 \mathrm{mg} / \mathrm{mL}) \text { and } \\
\text { agar }(1.5 \%)\end{array}$ & $\begin{array}{l}\text { Viability analysis of Escherichia } \\
\text { coli }\end{array}$ & [97] \\
\hline $\begin{array}{l}\text { Orange; Potato; } \\
\text { Drum stick }\end{array}$ & $\begin{array}{c}\text { Citrus sinensis; Solanum } \\
\text { tuberosum; Moringa } \\
\text { oleifera }\end{array}$ & $\begin{array}{l}\text { Peel powder of orange }(0.20 \mathrm{~g} / 100 \\
\mathrm{mL}) \text {, potato }(0.25 \mathrm{~g} / 100 \mathrm{~mL}) \text {, drum } \\
\text { stick }(1 \mathrm{~g} / 100 \mathrm{~mL}) \text { and agar }(2 \%)\end{array}$ & $\begin{array}{l}\text { Growth and pigment } \\
\text { production analysis of E. coli, } \\
\text { Serratia sp., Pseudomonas sp. }\end{array}$ & [89] \\
\hline $\begin{array}{l}\text { Banana; Melon; } \\
\text { Grapefruit }\end{array}$ & $\begin{array}{l}\text { Musa; Cucumis melo; } \\
\text { Citrus paradise }\end{array}$ & $\begin{array}{l}\text { Luria-Bertani medium contained } \\
1 \%(w / v) \text { starch, banana, grape } \\
\text { fruit and melon peel powder }\end{array}$ & $\begin{array}{l}\text { Amylase production from } \\
\text { Bacillus sp. AY3 }\end{array}$ & [10] \\
\hline Banana & Musa & $\begin{array}{l}\text { Autoclave banana peel directly } \\
\text { inoculated with fungi }\end{array}$ & $\begin{array}{c}\text { Growth of human fungal } \\
\text { pathogens viz. Lasiodiplodia } \\
\text { theobromae, Macrophomina } \\
\text { phaseolina, Nigrospora sphaerica, } \\
\text { Chaetomium murorum, Nattrassia } \\
\text { mangiferae and Schizophyllum } \\
\text { commune }\end{array}$ & [98] \\
\hline Watermelon & Citrullus lanatus & $\begin{array}{l}\text { Watermelon peel waste extract } \\
(500 \mathrm{~g} / \mathrm{L}) \text { and dextrose }(20 \mathrm{~g} / \mathrm{L})\end{array}$ & $\begin{array}{l}\text { Evaluation of fungal growth } \\
\text { such as Rhizopus oryzae, } \\
\text { Lichtheimia corymbifera, } \\
\text { Aspergillus niger, Penicillium } \\
\text { Expansium and Fusarium } \\
\text { oxysporum }\end{array}$ & [99] \\
\hline Orange & Citrus sinensis & $\begin{array}{l}\text { Orange peel extract }(19.8 \mathrm{~g} / \mathrm{L}) \\
\quad\left(\mathrm{NH}_{4}\right)_{2} \mathrm{SO}_{4}(0.6 \mathrm{~g} / \mathrm{L})\end{array}$ & $\begin{array}{l}\text { Biodiesel production using } \\
\text { oleaginous yeasts }\end{array}$ & [100] \\
\hline
\end{tabular}


Table 4. Cont.

\begin{tabular}{|c|c|c|c|c|}
\hline $\begin{array}{l}\text { Fruit/Vegetable } \\
\text { Common Name }\end{array}$ & Scientific Name & Medium Composition & Purpose/Utilization & Ref \\
\hline $\begin{array}{l}\text { Sponge gourd; } \\
\text { Lychee }\end{array}$ & $\begin{array}{l}\text { Luffa cylindrica; Litchi } \\
\text { chinensis }\end{array}$ & $\begin{array}{c}\text { Sponge gourd peel bed soaked } \\
\text { with urea }(0.3 \mathrm{~g} / \mathrm{L}),\left(\mathrm{NH}_{4}\right)_{2} \mathrm{SO}_{4} \\
(1.4 \mathrm{~g} / \mathrm{L}), \mathrm{KH}_{2} \mathrm{PO}_{4}(2.0 \mathrm{~g} / \mathrm{L}) \\
\mathrm{MgSO}_{4} 7 \mathrm{H}_{2} \mathrm{O}(0.3 \mathrm{~g} / \mathrm{L}), \text { peptone }(1 \\
\mathrm{g} / \mathrm{L}), \text { tween } 80(0.2 \mathrm{~g} / \mathrm{L}), \mathrm{FeSO}_{4} \\
7 \mathrm{H}_{2} \mathrm{O}(0.005 \mathrm{~g} / \mathrm{L}), \mathrm{MnSO}_{4} .7 \mathrm{H}_{2} \mathrm{O} \\
(0.0016 \mathrm{~g} / \mathrm{L}), \mathrm{ZnSO}_{4} .7 \mathrm{H}_{2} \mathrm{O}(0.0014 \\
\mathrm{g} / \mathrm{L}) \mathrm{CaCl}_{2} 2 \mathrm{H}_{2} \mathrm{O}(0.4 \mathrm{~g} / \mathrm{L}), \mathrm{CoCl}_{2} \\
6 \mathrm{H}_{2} \mathrm{O}(0.02 \mathrm{~g} / \mathrm{L}) ; \text { same } \\
\text { composition with lychee peel }\end{array}$ & $\begin{array}{l}\text { Cellulase production using } \\
\text { Trichoderma reesei }\end{array}$ & [101] \\
\hline Pea & Pisum sativum & $\begin{array}{c}\text { Pea peel powder soaked with urea } \\
(0.3 \mathrm{~g} / \mathrm{L}),\left(\mathrm{NH}_{4}\right)_{2} \mathrm{SO}_{4}(1.4 \mathrm{~g} / \mathrm{L}) \\
\mathrm{KH}_{2} \mathrm{PO}_{4}(2.0 \mathrm{~g} / \mathrm{L}), \mathrm{MgSO}_{4} .7 \mathrm{H}_{2} \mathrm{O} \\
(0.3 \mathrm{~g} / \mathrm{L}), \text { peptone }(1 \mathrm{~g} / \mathrm{L}), \text { tween } 80 \\
(0.2 \mathrm{~g} / \mathrm{L}), \mathrm{FeSO}_{4} 7 \mathrm{H}_{2} \mathrm{O}(0.005 \mathrm{~g} / \mathrm{L}) \\
\mathrm{MnSO}_{4} .7 \mathrm{H}_{2} \mathrm{O}(0.0016 \mathrm{~g} / \mathrm{L}), \mathrm{ZnSO} \mathrm{Zn}_{4} \\
7 \mathrm{H}_{2} \mathrm{O}(0.0014 \mathrm{~g} / \mathrm{L}) \mathrm{CaCl}_{2} .2 \mathrm{H}_{2} \mathrm{O} \\
(0.2 \mathrm{~g} / \mathrm{L}), \mathrm{CoCl}_{2} .6 \mathrm{H}_{2} \mathrm{O}(0.2 \mathrm{~g} / \mathrm{L})\end{array}$ & $\begin{array}{l}\text { Cellulase production using } \\
\text { Trichoderma reesei }\end{array}$ & [102] \\
\hline $\begin{array}{l}\text { Orange; Potato; } \\
\text { Drum stick }\end{array}$ & $\begin{array}{l}\text { Citrus sinensis; Solanum } \\
\text { tuberosum; Moringa } \\
\text { oleifera }\end{array}$ & $\begin{array}{l}\text { Peel powder of orange }(0.20 \mathrm{~g} / 100 \\
\mathrm{mL}) \text {, potato }(0.25 \mathrm{~g} / 100 \mathrm{~mL}) \text { drum } \\
\text { stick }(1 \mathrm{~g} / 100 \mathrm{~mL}) \text { and agar }(2.5 \%)\end{array}$ & $\begin{array}{c}\text { Growth analysis of Trichoderma } \\
\text { sp., Aspergillus sp. }\end{array}$ & [103] \\
\hline
\end{tabular}

Agar of Dragon fruit peel (DFP) was also used as a microbial growth media [92]. Grapefruit, banana and melon peels contain a high amount of carbohydrates, which act as a good substrate for the production of amylase [10]. Banana peel was found to be an economically low and effective medium for the growth of fungi [98]. The watermelon peel extract is found rich in macronutrients such as lipids, reducing sugars and total proteins [99]. The study reported that watermelon peel waste (WPW) was best for the growth of Aspergillus niger, Fusarium oxysporum, Lichtheimia corymbifera, Penicillium expansium and Rhizopus oryzae, respectively. The study also revealed that formulated watermelon peel waste dextrose agar (WPWDA) (watermelon peel waste dextrose agar) medium was found as an alternative way for some commonly used media such as Czapek's Dox agar (CzDA) and Potato dextrose agar (PDA); in addition, this medium was very cheap and eco-friendly. Orange peel waste (OPW) was used as a liquid medium in producing biodiesel used oleaginous yeasts and found that and Cryptococcus laurentii UCD 68-201 and Rhodosporidium toruloides NRRL 1091 strains yielded 31.9\% and $36.9 \%$ of biodiesel, respectively [100]. Pea peel waste was used as a growth medium at $30^{\circ} \mathrm{C}$ with Trichoderma reesei to produce cellulase enzyme [102].

\section{Fruit and Vegetable Peel Derived Biochar}

Biochar is a stable carbon-rich solid generated by pyrolysis as a result of the thermochemical decomposition of organic feedstock material at high temperatures under oxygen-free conditions [104]. Different types of food waste have been used for the production of biochar and its yield and physicochemical properties have been reported in detail $[105,106]$. Biochar is generally used to remove different types of pollutant containing heavy metals from contaminated water bodies [107-109]. It also serves as an intermediate for producing bioethanol from biological waste collected from food processing industries as well as different agricultural plant residues like husk, bran etc. [110,111]. Different studies have shown the production of biochar from different types of fruits and vegetables peel wastes (Table 5). 
Table 5. Fruits and vegetables peel derived biochar and its applications.

\begin{tabular}{|c|c|c|c|c|}
\hline $\begin{array}{l}\text { Fruit/Vegetable } \\
\text { Common Name }\end{array}$ & Scientific Name & $\begin{array}{l}\text { Process conditions Required } \\
\text { for Biochar Formation }\end{array}$ & Applications & Ref \\
\hline Orange; Banana & $\begin{array}{l}\text { Citrus sinensis; } \\
\quad \text { Musa }\end{array}$ & Pyrolysis at $500{ }^{\circ} \mathrm{C}$ for $10 \mathrm{~min}$ & $\begin{array}{l}\text { Showed good performance in } \\
\text { reducing the concentration of } \\
\text { biochemical oxygen demand } \\
\text { (BOD), chemical oxygen demand } \\
\text { (COD), total suspended solid (TSS) } \\
\text { and oil and grease of Palm oil Mil } \\
\text { effluent (POME) to an acceptable } \\
\text { level below the discharge }\end{array}$ & [112] \\
\hline Banana & Musa & $\begin{array}{l}\text { Hydrothermal carbonization at } \\
\qquad 230{ }^{\circ} \mathrm{C} \text { for } 2 \mathrm{~h}\end{array}$ & $\begin{array}{c}\text { Showed excellent lead } \\
\text { clarification capability of } 359 \mathrm{mg} / \mathrm{g} \\
\text { and } 193 \mathrm{mg} / \mathrm{g} \text {, respectively }\end{array}$ & [15] \\
\hline Pomelo & Citrus maxima & Pyrolysis at $450{ }^{\circ} \mathrm{C}$ for $1 \mathrm{~h}$ & $\begin{array}{l}\text { One gram of biochar adsorb } \\
150 \mathrm{mg} / \mathrm{L} \text { methyl orange dye }\end{array}$ & [113] \\
\hline Pineapple & Ananas comosus & Pyrolysis at $750{ }^{\circ} \mathrm{C}$ for $2 \mathrm{~h}$ & $\begin{array}{l}\text { Sorption capacity for hexavalent } \\
\text { chromium: Cr (VI) was } 7.44 \mathrm{mg} / \mathrm{g}\end{array}$ & [114] \\
\hline Pineapple & Ananas comosus & $\begin{array}{l}\text { Pyrolysis at } 200^{\circ} \mathrm{C} \text { for } 2 \mathrm{~h} \text { and } \\
\text { then heated at } 650^{\circ} \mathrm{C} \text { for } 3 \mathrm{~h}\end{array}$ & Sorption of oxytetracycline & [115] \\
\hline $\begin{array}{l}\text { Orange; Pineapple; } \\
\text { Dragon fruit }\end{array}$ & $\begin{array}{c}\text { Citrus sinensis; } \\
\text { Ananas comosus; } \\
\text { Hylocereus undatus }\end{array}$ & Pyrolysis at $300^{\circ} \mathrm{C}$ for $2 \mathrm{~h}$ & $\begin{array}{l}\text { Maximum ammonium cation } \\
\left(\mathrm{NH}^{4+}\right) \text { adsorption capacities } \\
\text { were associated with biochars of } \\
\text { orange peel }(4.71 \mathrm{mg} / \mathrm{g}) \text { and } \\
\text { pineapple peel }(5.60 \mathrm{mg} / \mathrm{g}) \\
\text { produced at } 300^{\circ} \mathrm{C} \text { for } 2 \mathrm{~h} \text {. The } \\
\text { maximum } \mathrm{NH}^{4+} \text { adsorption } \\
\text { capacity of the dragon fruit } \\
\text { (pitaya) peel biochar produced at } \\
400{ }^{\circ} \mathrm{C} \text { for } 2 \mathrm{~h} \text { was } 2.65 \mathrm{mg} / \mathrm{g}\end{array}$ & [116] \\
\hline Pomelo & Citrus maxima & Pyrolysis at $450{ }^{\circ} \mathrm{C}$ for $1 \mathrm{~h}$ & $\begin{array}{l}\text { A } 0.05 \mathrm{~g} \text { of biochar adsorbed } \\
57.637 \mathrm{mg} / \mathrm{g} \text { of } \mathrm{Cr}(\mathrm{VI})\end{array}$ & [117] \\
\hline Litchi & Litchi chinensis & $\begin{array}{l}\text { Hydrothermal carbonization at } \\
\qquad 180^{\circ} \mathrm{C} \text { for } 12 \mathrm{~h}\end{array}$ & $\begin{array}{c}\text { Adsorption capacity for congored } \\
\text { and malachite green was } 404.4 \\
\text { and } 2468 \mathrm{mg} / \mathrm{g}\end{array}$ & [118] \\
\hline Rambutan & $\begin{array}{l}\text { Nephelium } \\
\text { lappaceum }\end{array}$ & Pyrolysis at $600{ }^{\circ} \mathrm{C}$ for $3 \mathrm{~h}$ & $\begin{array}{l}\text { Adsorption for removal of copper } \\
\text { ion: } \mathrm{Cu} \text { (II) from aqueous } \\
\text { solutions of } 50 \text { and } 100 \mathrm{mg} / \mathrm{L} \text { at } 0.2 \\
\text { and } 0.4 \mathrm{~g} / \mathrm{L} \text { adsorbent dosages, } \\
\text { respectively }\end{array}$ & [119] \\
\hline Pomegranate & Punica granatum & Pyrolysis at $300^{\circ} \mathrm{C}$ for $2 \mathrm{~h}$ & Adsorption of $\mathrm{Cu}(\mathrm{II})$ was $52 \mathrm{mg} / \mathrm{g}$ & [120] \\
\hline Sweet lime & Citrus limetta & Pyrolysis at $450{ }^{\circ} \mathrm{C}$ for $1 \mathrm{~h}$ & $\begin{array}{l}\text { Maximum removal efficiency was } \\
\text { found to be } 95 \% \text { with } 120 \mathrm{mg} / \mathrm{L} \text { of } \\
\text { initial } \mathrm{Cr}(\mathrm{VI}) \text { concentration with } \\
\qquad 3 \mathrm{~g} / \mathrm{L} \text { of biochar dose }\end{array}$ & [121] \\
\hline Potato & Solanum tuberosum & Pyrolysis at $500{ }^{\circ} \mathrm{C}$ for $5 \mathrm{~min}$ & $\begin{array}{l}\text { Hydrogen sulfide }\left(\mathrm{H}_{2} \mathrm{~S}\right) \text { was } \\
\text { achieved } 53 \mathrm{mg} / \mathrm{g} \text { at } 500{ }^{\circ} \mathrm{C} \text {, under } \\
\text { space velocity }\left(8000 \mathrm{~L} \mathrm{~min}^{-1} \mathrm{~kg}^{-1}\right)\end{array}$ & [122] \\
\hline
\end{tabular}

Potato peel waste (PPW) was used to produce biochar by fast pyrolysis using the fluidized bed system to remove $\mathrm{H}_{2} \mathrm{~S}$ [122]. Biochar produced from pineapple peel showed that $\mathrm{H}$-bonding interacts with oxytetracycline (OTC) for its sorption. However, thermodynamic parameters showed that the OTC sorption onto the biochar was endothermic and is a spontaneous process [115]. Biochar derived from pineapple, sweet lime and pomelo peel was developed to remove hexavalent chromium from aqueous solution $[114,117,121]$. In another report, biochar was prepared from rambutan and pomegranate peel for the removal of copper (II) ions from aqueous and soil system, respectively [118,119]. Biochar derived from pomelo and litchi peels were used to remove congo red, methyl orange and malachite green from wastewater [113,118].

\section{Fruit and Vegetable Peel Derived Biosorbents}

Biosorption can be explained as a mechanism when a sorbate (i.e., an atom, ion or compound) reacts with the biomass or biomaterial (stated as biosorbent), which causes the acclimatization of 
sorbate ions over the surface of biosorbents, which subsequently reduces the sorbate concentration in the solution [123]. This mechanism has attained significant attention due to its ability to immobilize the heavy metal contaminated from the water (especially contaminated with the discharge of electroplating and mining industries) or metal processing industries. Numerous biosorbents have been developed with the help of different biomasses such as algae, fungi (e.g., Mucorrouxii), yeasts and bacteria (e.g., Bacillus thuringiensis) $[124,125]$. The natural biomass complex compendium signifies the contribution of different processes that describe the mechanism of how biosorbents works in eliminating the various contaminants; however, these processes are still being explored. Several functional groups are attached to these biosorbents to attract and sequester the contaminants, which relies on the type of biosorbent and functional groups (amine, amides carboxyl, hydroxyl, carbonyl, sulfhydryl, phenolic, sulfonate and phosphate groups) attached to it [126,127].

Many studies were done to produce biosorbents from fruits peel, i.e., apple, pineapple and dragon fruit and vegetables peel such as garlic, and cucumber to remove methylene blue dye from the aqueous solution (Table 6) [16,128-131].

Table 6. Fruits and vegetables peel derived biosorbents and their applications.

\begin{tabular}{|c|c|c|c|c|}
\hline $\begin{array}{l}\text { Fruit/Vegetable } \\
\text { Common Name }\end{array}$ & Scientific Name & $\begin{array}{c}\text { Drying } \\
\text { Temperature/Time }\end{array}$ & Applications & Ref \\
\hline Apple & Malus domestica & $60^{\circ} \mathrm{C} / 24 \mathrm{~h}$ & $\begin{array}{l}\text { Adsorbed } 107.52 \mathrm{mg} / \mathrm{g} \text { of } \\
\text { methylene blue }\end{array}$ & [16] \\
\hline Dragon fruit & Hylocereus undatus & $105^{\circ} \mathrm{C} / 24 \mathrm{~h}$ & $\begin{array}{l}\text { A dosage of } 0.06 \mathrm{~g} \text { adsorbed } \\
192.31 \mathrm{mg} / \mathrm{g} \text { of methylene blue }\end{array}$ & [131] \\
\hline Pineapple & Ananas comosus & $70^{\circ} \mathrm{C} / 48 \mathrm{~h}$ & $\begin{array}{l}\text { Adsorbed } 97.09 \mathrm{mg} / \mathrm{g} \text { of } \\
\text { methylene blue }\end{array}$ & [129] \\
\hline Grapefruit & Citrus paradisi & $105^{\circ} \mathrm{C} / 24 \mathrm{~h}$ & $\begin{array}{l}\text { Adsorbed } 52.48 \mathrm{mg} / \mathrm{g} \text { copper ion: } \\
\qquad \mathrm{Cu}(\mathrm{II})\end{array}$ & [132] \\
\hline Banana & Musa paradisiaca & $60{ }^{\circ} \mathrm{C} / 5 \mathrm{~h}$ & $\begin{array}{l}\text { Removed } 90 \% \text { lead (II) and cadmium } \\
\text { (II) ions }\end{array}$ & [133] \\
\hline Langast & Lansium domesticum & $60^{\circ} \mathrm{C} / 24 \mathrm{~h}$ & Adsorbed $10.1 \mathrm{mg} / \mathrm{g}$ of nickel & {$[134]$} \\
\hline $\begin{array}{c}\text { Ponkan fruits/Mandarin } \\
\text { orange }\end{array}$ & Citrus reticulata & RT/days & Adsorbed $112.1 \mathrm{mg} / \mathrm{g}$ of lead (II) ions & {$[135]$} \\
\hline Banana & Musa & $80^{\circ} \mathrm{C} / 48 \mathrm{~h}$ & $\begin{array}{l}\text { Adsorbed } 97 \mathrm{mg} / \mathrm{g} \text { color, } 25 \mathrm{mg} / \mathrm{g} \text { TSS, } \\
\text { and } 90.5 \mathrm{mg} / \mathrm{g} \text { COD removed from } \\
\text { Palm oil mill effluent (Natural banana } \\
\text { peel); Adsorbed } 137.5 \mathrm{mg} / \mathrm{g}, 28.5 \mathrm{mg} / \mathrm{g} \\
\text { and } 93 \mathrm{mg} / \mathrm{g} \text { for color, TSS and COD } \\
\text { removed (Methylated banana peel) }\end{array}$ & [136] \\
\hline $\begin{array}{c}\text { Ponkan fruits/Mandarin } \\
\text { orange }\end{array}$ & Citrus reticulata & $60^{\circ} \mathrm{C} / 24 \mathrm{~h}$ & $\begin{array}{c}\text { Adsorbed } 1.92,1.37 \text { and } 1.31 \mathrm{mmol} / \mathrm{g} \\
\text { of nickel (II), cobalt (II) and copper } \\
\text { (II) ions }\end{array}$ & [137] \\
\hline Banana & Musa & $\mathrm{RT} / 4$ days & $\begin{array}{c}\text { A dosage of } 0.3 \mathrm{~g} \text { adsorbed } 81.07 \% \text { of } \\
\text { rhodamine-B }\end{array}$ & [138] \\
\hline Bottle gourd & Lagenaria siceraria & $80^{\circ} \mathrm{C} / 24 \mathrm{~h}$ & $\begin{array}{c}\text { Adsorbed } 99 \% \text { copper, } 95 \% \text { silver } \\
\text { and iron }\end{array}$ & [139] \\
\hline Sponge gourd & Luffa acutangula & $60^{\circ} \mathrm{C} / 24 \mathrm{~h}$ & $\begin{array}{c}\text { A dosage of } 8 \mathrm{~g} / \mathrm{L} \text { adsorbed } 69.64 \\
\mathrm{mg} / \mathrm{g} \text { of malachite green }\end{array}$ & {$[140]$} \\
\hline Potato; Carrot & $\begin{array}{l}\text { Solanum tuberosum/ } \\
\text { Daucus carota subsp. } \\
\text { sativus }\end{array}$ & $60^{\circ} \mathrm{C} / 48 \mathrm{~h}$ & $\begin{array}{c}\text { A dosage of } 3.0 \mathrm{~g} \text { adsorbed } 79.32 \% \\
\text { of nickel }\end{array}$ & [141] \\
\hline Cucumber & Cucumis satious & $95^{\circ} \mathrm{C} / 24 \mathrm{~h}$ & $\begin{array}{l}\text { A dosage of } 4 \mathrm{~g} / \mathrm{L} \text { adsorbed } 81.4 \% \\
\text { methylene blue }\end{array}$ & [130] \\
\hline Garlic & Allium sativum & $60^{\circ} \mathrm{C} / 24 \mathrm{~h}$ & $\begin{array}{l}\text { Adsorbed } 142.86 \mathrm{mg} / \mathrm{g} \text { of } \\
\text { methylene blue }\end{array}$ & [128] \\
\hline
\end{tabular}


Sponge gourd peel was considered as an inexpensive natural biosorbent to remove malachite green (MG), a cationic dye, in batch mode [140]. Banana peel was used as an efficient biosorbent for removing rhodamine-B, a cationic water-soluble dye of basic nature [138]. The contact time selected for the adsorption of rhodamine-B on banana peel powder was $60 \mathrm{~min}$. In another study, a bisorbent was developed by using natural banana peel (NBP), methylated banana peel (MBP) and banana peel activated carbon (BPAC), respectively, and used in the treatment of palm oil mill effluent (POME) [136].

\section{Conclusions}

Development of the sustainable solution for managing fruit and vegetable waste has become extremely important in present scenario. Therefore, it demands the development of solution that could utilize the full potential of these waste material and support in attaining the social, environmental and economic benefits from these wastes. Furthermore, utilization of the fruit as well as vegetable waste especially peels in developing value-added products such as edible films, probiotics, nanoparticles, carbon dots, biochar and biosorbents will be an eco-friendly and sustainable way to create novel business opportunities and also functionalizing this waste for a useful purpose. Most of these interventions are in its infancy stage and lacks the technological advances and findings. Hence, there is high need to develop consortia of researcher and industrialist to improve the economic potential of these valuable horticultural wastes with a support of initial investment. Moreover, it will aid in promoting the usage of horticultural waste for synthesizing value-added commodities.

Author Contributions: Conceptualization, E.N., K.K. and D.K.; Manuscript writing, H.K., K.B. and R.S.; Manuscript editing, E.N., D.S.D., R.V. and P.B.; Critical revising, K.K., S.S. and D.K. All authors have read and agreed to the published version of the manuscript.

Funding: This research was funded by the Excellence project, UHK.

Acknowledgments: We acknowledge the University of Hradec Kralove (Faculty of Science, VT2019-2021) for financial support.

Conflicts of Interest: The authors declare no conflict of interest.

\section{References}

1. Plazzotta, S.; Manzocco, L.; Nicoli, M.C. Fruit and vegetable waste management and the challenge of fresh-cut salad. Trends Food Sci. Technol. 2017, 63, 51-59. [CrossRef]

2. National Academy of Agricultural Sciences. Saving the Harvest: Reducing the Food Loss and Waste; Policy Brief No. 5.; National Academy of Agricultural Sciences: New Delhi, India, 2019. Available online: http://naasindia.org/documents/Saving\%20the\%20Harvest.pdf (accessed on 8 October 2019).

3. Chang, J.I.; Tsai, J.J.; Wu, K.H. Composting of vegetable waste. Waste Manag. Res. 2006, 24, 354-362. [CrossRef] [PubMed]

4. Panda, S.K.; Mishra, S.S.; Kayitesi, E.; Ray, R.C. Microbial-processing of fruit and vegetable wastes for production of vital enzymes and organic acids: Biotechnology and scopes. Environ. Res. 2016, 146, 161-172. [CrossRef] [PubMed]

5. Galanakis, C.M. Recovery of high added-value components from food wastes: Conventional, emerging technologies and commercialized applications. Trends Food Sci. Technol. 2012, 26, 68-87. [CrossRef]

6. Rudra, S.G.; Nishad, J.; Jakhar, N.; Kaur, C. Food industry waste: Mine of nutraceuticals. Int. J. Sci. Environ. 2015, 4, 205-229.

7. Gorinstein, S.; Martín-Belloso, O.; Park, Y.-S.; Haruenkit, R.; Lojek, A.; Cížz, M.; Caspi, A.; Libman, I.; Trakhtenberg, S. Comparison of some biochemical characteristics of different citrus fruits. Food Chem. 2001, 74, 309-315. [CrossRef]

8. Soong, Y.-Y.; Barlow, P.J. Antioxidant activity and phenolic content of selected fruit seeds. Food Chem. 2004, 88, 411-417. [CrossRef] 
9. Sagar, N.A.; Pareek, S.; Sharma, S.; Yahia, E.M.; Lobo, M.G. Fruit and Vegetable Waste: Bioactive Compounds, Their Extraction, and Possible Utilization. Compr. Rev. Food Sci. Food Saf. 2018, 17, 512-531. [CrossRef]

10. Siddiqui, A.; Salahuddin, T.; Riaz, A.; Zohra, R.R.; Naheed, S. Production of amylase from Bacillus sp. AY3 using fruit peels as substrate. FUUAST J. Biol. 2014, 4, 213-215.

11. Santo, A.P.D.E.; Cartolano, N.S.; Silva, T.F.; Soares, F.A.S.D.M.; Gioielli, L.; Perego, P.; Converti, A.; De Oliveira, M.N. Fibers from fruit by-products enhance probiotic viability and fatty acid profile and increase CLA content in yoghurts. Int. J. Food Microbiol. 2012, 154, 135-144. [CrossRef]

12. Shanmugavadivu, M.; Kuppusamy, S.; Ranjithkumar, R. Synthesis of pomegranate peel extract mediated silver nanoparticles and its antibacterial activity. Am. J. Adv. Drug. Deliv. 2014, 2, 174-182.

13. Nasirifar, S.Z.; Maghsoudlou, A.; Oliyaei, N. Effect of active lipid-based coating incorporated with nanoclay and orange peel essential oil on physicochemical properties of Citrus sinensis. Food Sci. Nutr. 2018, 6, 1508-1518. [CrossRef] [PubMed]

14. Jiao, X.-Y.; Li, L.-S.; Qin, S.; Zhang, Y.; Huang, K.; Xu, L. The synthesis of fluorescent carbon dots from mango peel and their multiple applications. Colloids Surfaces A: Physicochem. Eng. Asp. 2019, 577, 306-314. [CrossRef]

15. Zhou, N.; Chen, H.; Xi, J.; Yao, D.; Zhou, Z.; Tian, Y.; Lu, X. Biochars with excellent Pb(II) adsorption property produced from fresh and dehydrated banana peels via hydrothermal carbonization. Bioresour. Technol. 2017, 232, 204-210. [CrossRef]

16. Enniya, I.; Jourani, A. Study of Methylene Blue Removal by a biosorbent prepared with Apple peels. J. Mater. Environ. Sci. 2017, 8, 4573-4581. [CrossRef]

17. Zaragoza, M.D.L.L.Z.; González-Reza, R.M.; Mendoza-Munoz, N.; Miranda-Linares, V.; Bernal-Couoh, T.F.; Mendoza-Elvira, S.; Quintanar-Guerrero, D. Nanosystems in Edible Coatings: A Novel Strategy for Food Preservation. Int. J. Mol. Sci. 2018, 19, 705. [CrossRef]

18. Wu, Y.; Luo, Y.; Wang, Q. Antioxidant and antimicrobial properties of essential oils encapsulated in zein nanoparticles prepared by liquid-liquid dispersion method. LWT 2012, 48, 283-290. [CrossRef]

19. Prakash, A.; Baskaran, R.; Vadivel, V. Citral nanoemulsion incorporated edible coating to extend the shelf life of fresh cut pineapples. LWT 2020, 118, 108851. [CrossRef]

20. Raghav, P.K.; Agarwal, N.; Saini, M. Edible coating of fruits and vegetables: A review. Int. J. Sci. Res. Mod. Edu. 2016, 1, 188-204.

21. Ullah, A.; Abbasi, N.; Shafique, M.; Qureshi, A.A. Influence of Edible Coatings on Biochemical Fruit Quality and Storage Life of Bell Pepper cv. "Yolo Wonder.". J. Food Qual. 2017, 2017, 1-11. [CrossRef]

22. Adukwu, E.; Allen, S.C.; Phillips, C.A. The anti-biofilm activity of lemongrass (Cymbopogon flexuosus) and grapefruit (Citrus paradisi) essential oils against five strains of Staphylococcus aureus. J. Appl. Microbiol. 2012, 113, 1217-1227. [CrossRef] [PubMed]

23. Alparslan, Y.; Metin, C.; Yapıcı, H.H.; Baygar, T.; Günlü, A.; Baygar, T. Combined effect of orange peel essential oil and gelatin coating on the quality and shelf life of shrimps. J. Food Saf. Food Qual. 2017, 68, 69-78.

24. Etxabide, A.; Urdanpilleta, M.; Gómez-Arriaran, I.; De La Caba, K.; Guerrero, P. Effect of pH and lactose on cross-linking extension and structure of fish gelatin films. React. Funct. Polym. 2017, 117, 140-146. [CrossRef]

25. Hanani, Z.A.N.; Yee, F.C.; Nor-Khaizura, M. Effect of pomegranate (Punica granatum L.) peel powder on the antioxidant and antimicrobial properties of fish gelatin films as active packaging. Food Hydrocoll. 2019, 89, 253-259. [CrossRef]

26. Shin, S.-H.; Chang, Y.; Lacroix, M.; Han, J. Control of microbial growth and lipid oxidation on beef product using an apple peel-based edible coating treatment. LWT 2017, 84, 183-188. [CrossRef]

27. Al-Anbari, I.H.; Dakhel, A.M.; Adnan, A. The effect of adding local orange peel powder to microbial inhibition and oxidative reaction within edible film component. Plant Arc. 2019, 19, 1006-1012.

28. Moghadam, M.; Salami, M.; Mohammadian, M.; Khodadadi, M.; Emam-Djomeh, Z. Development of antioxidant edible films based on mung bean protein enriched with pomegranate peel. Food Hydrocoll. 2020. [CrossRef]

29. Tammineni, N.; Ünlü, G.; Min, S.C. Development of antimicrobial potato peel waste-based edible films with oregano essential oil to inhibit Listeria monocytogenes on cold-smoked salmon. Int. J. Food Sci. Tech. 2013, 48, 211-214. [CrossRef] 
30. Alparslan, Y.; Baygar, T. Effect of Chitosan Film Coating Combined with Orange Peel Essential Oil on the Shelf Life of Deepwater Pink Shrimp. Food Bioprocess Technol. 2017, 10, 842-853. [CrossRef]

31. Rahmawati, D.; Chandra, M.; Santoso, S.; Puteri, M.G. Application of lemon peel essential oil with edible coating agent to prolong shelf life of tofu and strawberry. In AIP Conference Proceedings; AIP Publishing LLC: Melville, NY, USA, 2017. [CrossRef]

32. Radi, M.; Akhavan, H.-R.; Amiri, S.; Akhavan-Darabi,S. The use of orange peel essential oil microemulsion and nanoemulsion in pectin-based coating to extend the shelf life of fresh-cut orange. J. Food Process. Preserv. 2017. [CrossRef]

33. Borah, P.P.; Das, P.; Badwaik, L.S. Ultrasound treated potato peel and sweet lime pomace based biopolymer film development. Ultrason. Sonochem. 2017, 36, 11-19. [CrossRef] [PubMed]

34. Hanani, Z.A.N.; Husna, A.A.; Syahida, S.N.; Khaizura, M.N.; Jamilah, B. Effect of different fruit peels on the functional properties of gelatin/polyethylene bilayer films for active packaging. Food Packag. Shelf Life 2018, 18, 201-211. [CrossRef]

35. Abdel-Hamid, M.; Romeih, E.; Huang, Z.; Enomoto, T.; Huang, L.; Li, L. Bioactive properties of probiotic set-yogurt supplemented with Siraitia grosvenorii fruit extract. Food Chem. 2019. [CrossRef]

36. Cerezal, P.; Duarte, G. Use of skin in the elaboration of concentrated products of cactus pear (Opuntia ficus-indica (L.) Miller). J. Prof. Assoc. Cactus. 2005, 7, 61-83.

37. Crizel, T.D.M.; Jablonski, A.; Rios, A.D.O.; Rech, R.; Flôres, S.H. Dietary fiber from orange byproducts as a potential fat replacer. LWT 2013, 53, 9-14. [CrossRef]

38. Chan, C.-L.; Gan, R.-Y.; Shah, N.P.; Corke, H. Enhancing antioxidant capacity of Lactobacillus acidophilus-fermented milk fortified with pomegranate peel extracts. Food Biosci. 2018, 26, 185-192. [CrossRef]

39. Coelho, E.M.; Souza, M.E.; Corrêa, L.C.; Viana, A.C.; De Azevêdo, L.C.; Lima, M.D.S. Bioactive Compounds and Antioxidant Activity of Mango Peel Liqueurs (Mangifera indica L.) Produced by Different Methods of Maceration. Antioxidants 2019, 8, 102. [CrossRef]

40. Drago, L. Probiotics and Colon Cancer. Microorganisms 2019, 7, 66. [CrossRef]

41. Sah, B.N.P.; Vasiljevic, T.; McKechnie, S.; Donkor, O. Effect of pineapple waste powder on probiotic growth, antioxidant and antimutagenic activities of yogurt. J. Food Sci. Technol. 2015, 53, 1698-1708. [CrossRef]

42. Vicenssuto, G.M.; De Castro, R.J.S. Development of a novel probiotic milk product with enhanced antioxidant properties using mango peel as a fermentation substrate. Biocatal. Agric. Biotechnol. 2020, 24, 101564. [CrossRef]

43. Pgi, D.; Jwa, S.; Rmusk, R. Formulation and development of composite fruit peel powder incorporated fat and sugar-free probiotic set yogurt. GSC Boil. Pharm. Sci. 2020, 11, 93-99. [CrossRef]

44. Akhtar, M.S.; Panwar, J.; Yun, Y.-S. Biogenic Synthesis of Metallic Nanoparticles by Plant Extracts. ACS Sustain. Chem. Eng. 2013, 1, 591-602. [CrossRef]

45. Ghosh, P.R.; Fawcett, D.; Sharma, S.B.; Poinern, G.E.J. Production of High-Value Nanoparticles via Biogenic Processes Using Aquacultural and Horticultural Food Waste. Materials 2017, 10, 852. [CrossRef] [PubMed]

46. Shah, M.; Fawcett, D.; Sharma, S.; Tripathy, S.K.; Poinern, G.E.J. Green Synthesis of Metallic Nanoparticles via Biological Entities. Materials 2015, 8, 7278-7308. [CrossRef]

47. Fawcett, D.; Verduin, J.; Shah, M.; Sharma, S.B.; Poinern, G.E.J. A Review of Current Research into the Biogenic Synthesis of Metal and Metal Oxide Nanoparticles via Marine Algae and Seagrasses. J. Nanosci. 2017, 2017, 1-15. [CrossRef]

48. Anastas, P.T.; Warner, J.C. Green Chemistry: Theory and Practice; Oxford University Press: Oxford, UK, 2000.

49. Thakkar, K.; Mhatre, S.S.; Parikh, R.Y. Biological synthesis of metallic nanoparticles. Nanomed. Nanotech. Boil. Med. 2010, 6, 257-262. [CrossRef]

50. Kumar, H.; Bhardwaj, K.; Kuca, K.; Kalia, A.; Nepovimova, E.; Verma, R.; Kumar, D. Flower-Based Green Synthesis of Metallic Nanoparticles: Applications beyond Fragrance. Nanomaterials 2020, 10, 766. [CrossRef]

51. Naganathan, K.; Thirunavukkarasu, S. Green way genesis of silver nanoparticles using multiple fruit peels waste and its antimicrobial, anti-oxidant and anti-tumor cell line studies. In Proceedings of the IOP Conference Series: Materials Science and Engineering; IOP Publishing: Bristol, UK, 2017; Volume 191, p. 12009. 
52. Shet, A.R.; Tantri, S.; Bennal, A. Economical biosynthesis of silver nanoparticles using fruit waste. J. Chem. Pharm. Sci. 2016, 9, 2306-2311.

53. Reenaa, M.; Menon, A.S. Synthesis of Silver Nanoparticles from Different Citrus Fruit Peel Extracts and a Comparative Analysis on its Antibacterial Activity. Int. J. Curr. Microbiol. Appl. Sci. 2017, 6, 2358-2365. [CrossRef]

54. Skiba, M.I.; Vorobyova, V.I. Synthesis of Silver Nanoparticles Using Orange Peel Extract Prepared by Plasmochemical Extraction Method and Degradation of Methylene Blue under Solar Irradiation. Adv. Mater. Sci. Eng. 2019, 2019, 1-8. [CrossRef]

55. Samreen, F.G.; Muzaffar, R.; Nawaz, M.; Gul, S.; Basra, M.A.R. Synthesis, Characterization and Anti-Microbial Activity of Citrus limon Mediated Nanoparticles. Preprints 2018, 2018110417. [CrossRef]

56. Ibrahim, H.M.M. Green synthesis and characterization of silvernanoparticles using banana peel extract and their antimicrobial activity against representative microorganisms. J. Radiat. Res. Appl. Sci. 2015, 8, 265-275. [CrossRef]

57. Devanesan, S.; AlSalhi, M.; Balaji, R.V.; A Ranjitsingh, A.J.; Ahamed, A.; Alfuraydi, A.; Alqahtani, F.Y.; Aleanizy, F.S.; Othman, A.H. Antimicrobial and Cytotoxicity Effects of Synthesized Silver Nanoparticles from Punica granatum Peel Extract. Nanoscale Res. Lett. 2018, 13, 315. [CrossRef] [PubMed]

58. Ajmal, N.; Saraswat, K.; Sharma, V.; Zafar, M.E. Synthesis and antibacterial activity of silver nanoparticles from Prunus armeniaca (Apricot) fruit peel extract. Bull. Environ. Pharmacol. Life Sci. 2016, 5, 91-94.

59. Kokila, T.; Ramesh, P.S.; Geetha, D. Biosynthesis of silver nanoparticles from Cavendish banana peel extract and its antibacterial and free radical scavenging assay: A novel biological approach. Appl. Nanosci. 2015, 5, 911-920. [CrossRef]

60. Barros, C.H.N.; Cruz, G.C.F.; Mayrink, W.; Tasic, L. Bio-based synthesis of silver nanoparticles from orange waste: Effects of distinct biomolecule coatings on size, morphology, and antimicrobial activity. Nanotechnol. Sci. Appl. 2018, 11, 1-14. [CrossRef] [PubMed]

61. Nava, O.; Soto-Robles, C.; Gómez-Gutiérrez, C.; Vilchis-Nestor, A.; Castro-Beltrán, A.; Olivas, A.; Morales, P.L. Fruit peel extract mediated green synthesis of zinc oxide nanoparticles. J. Mol. Struct. 2017, 1147, 1-6. [CrossRef]

62. Das, G.; Patra, J.K.; Basavegowda, N.; Vishnuprasad, C.N.; Shin, H.-S. Comparative study on antidiabetic, cytotoxicity, antioxidant and antibacterial properties of biosynthesized silver nanoparticles using outer peels of two varieties of Ipomoea batatas (L.) Lam. Int. J. Nanomed. 2019, 14, 4741-4754. [CrossRef]

63. Bhuvaneswari, S.; Subashini, G.; Subramaniyam, S. Green synthesis of zinc oxide nanoparticles using potato peel and degradation of textile mill effluent by photocatalytic activity. World J. Pharm. Res. 2017, 6, 774-785. [CrossRef]

64. Patra, J.K.; Kwon, Y.; Baek, K.-H. Green biosynthesis of gold nanoparticles by onion peel extract: Synthesis, characterization and biological activities. Adv. Powder Technol. 2016, 27, 2204-2213. [CrossRef]

65. Kumar, V.; Verma, S.; Choudhury, S.; Tyagi, M.; Chatterjee, S.; Variyar, P.S. Biocompatible silver nanoparticles from vegetable waste: Its characterization and bio-efficacy. Int. J. Nanomater. Sci. 2015, 4, 70-86.

66. Tamileswari, R.; Nisha, M.H.; Jesurani, S.; Kanagesan, S.; Hashim, M.; Catherine, S.; Alexander, P. Synthesis of silver nanoparticles using the vegetable extract of Raphanus sativus (radish) and assessment of their antibacterial activity. Int. J. Adv. Technol. Eng. Sci. 2015, 3, 207-212.

67. Fan, H.; Zhang, M.; Bhandari, B.; Yang, C.-H. Food waste as a carbon source in carbon quantum dots technology and their applications in food safety detection. Trends Food Sci. Technol. 2020, 95, 86-96. [CrossRef]

68. Kumar, H.; Kuča, K.; Bhatia, S.K.; Saini, K.; Kaushal, A.; Verma, R.; Bhalla, T.C.; Kumar, D. Applications of Nanotechnology in Sensor-Based Detection of Foodborne Pathogens. Sensors 2020, 20, 1966. [CrossRef]

69. Wang, Y.; Hu, A. Carbon quantum dots: Synthesis, properties and applications. J. Mater. Chem. C 2014, 2, 6921. [CrossRef]

70. Ajila, C.; Bhat, S.; Rao, U.P. Valuable components of raw and ripe peels from two Indian mango varieties. Food Chem. 2007, 102, 1006-1011. [CrossRef]

71. Rattanapoltee, P.; Kaewkannetra, P. Utilization of Agricultural Residues of Pineapple Peels and Sugarcane Bagasse as Cost-Saving Raw Materials in Scenedesmus acutus for Lipid Accumulation and Biodiesel Production. Appl. Biochem. Biotechnol. 2014, 173, 1495-1510. [CrossRef]

72. Pérez-Jiménez, J.; Saura-Calixto, F. Fruit peels as sources of non-extractable polyphenols or macromolecular antioxidants: Analysis and nutritional implications. Food Res. Int. 2018, 111, 148-152. [CrossRef] 
73. Cao, L.; Meziani, M.J.; Sahu, S.; Sun, Y.-P. Photoluminescence Properties of Graphene versus Other Carbon Nanomaterials. Accounts Chem. Res. 2012, 46, 171-180. [CrossRef]

74. Iravani, S.; Varma, R.S. Green synthesis, biomedical and biotechnological applications of carbon and graphene quantum dots. A review. Environ. Chem. Lett. 2020, 18, 703-727. [CrossRef] [PubMed]

75. Tyagi, A.; Tripathi, K.M.; Choudhary, S.; Singh, N.; Gupta, R.K. Green synthesis of carbon quantum dots from lemon peel waste: Applications in sensing and photocatalysis. RSC Adv. 2016, 6, 72423-72432. [CrossRef]

76. Huang, C.-C.; Hung, Y.-S.; Weng, Y.-M.; Chen, W.; Lai, Y.-S. Sustainable development of carbon nanodots technology: Natural products as a carbon source and applications to food safety. Trends Food Sci. Technol. 2019, 86, 144-152. [CrossRef]

77. Vandarkuzhali, S.A.A.; Natarajan, S.; Jeyabalan, S.; Sivaraman, G.; Singaravadivel, S.; Muthusubramanian, S.; Viswanathan, B. Pineapple Peel-Derived Carbon Dots: Applications as Sensor, Molecular Keypad Lock, and Memory Device. ACS Omega 2018, 3, 12584-12592. [CrossRef] [PubMed]

78. Ghosh, S.; Ghosal, K.; Mohammad, S.A.; Sarkar, K. Dendrimer functionalized carbon quantum dot for selective detection of breast cancer and gene therapy. Chem. Eng. J. 2019, 373, 468-484. [CrossRef]

79. Huang, Q.; Lin, X.; Zhu, J.J.; Tong, Q.X. Pd-Au@ carbon dots nanocomposite: Facile synthesis and application as an ultrasensitive electrochemical biosensor for determination of colitoxin DNA in human serum. Biosens. Bioelectron. 2017, 94, 507-512. [CrossRef]

80. Lu, W.; Qin, X.; Liu, S.; Chang, G.; Zhang, Y.; Luo, Y.; Asiri, A.M.; Al-Youbi, A.O.; Sun, X. Economical, Green Synthesis of Fluorescent Carbon Nanoparticles and Their Use as Probes for Sensitive and Selective Detection of Mercury(II) Ions. Anal. Chem. 2012, 84, 5351-5357. [CrossRef]

81. Xiao, P.; Ke, Y.; Lu, J.; Huang, Z.; Zhu, X.; Wei, B.; Huang, L. Photoluminescence immunoassay based on grapefruit peel-extracted carbon quantum dots encapsulated into silica nanospheres for p53 protein. Biochem. Eng. J. 2018, 139, 109-116. [CrossRef]

82. Bankoti, K.; Rameshbabu, A.P.; Datta, S.; Das, B.; Mitra, A.; Dhara, S. Onion derived carbon nanodots for live cell imaging and accelerated skin wound healing. J. Mater. Chem. B 2017, 5, 6579-6592. [CrossRef]

83. Zhou, J.; Sheng, Z.; Han, H.-Y.; Zhou, M.; Li, C. Facile synthesis of fluorescent carbon dots using watermelon peel as a carbon source. Mater. Lett. 2012, 66, 222-224. [CrossRef]

84. Chatzimitakos, T.; Kasouni, A.; Sygellou, L.; Avgeropoulos, A.; Troganis, A.; Stalikas, C. Two of a kind but different: Luminescent carbon quantum dots from Citrus peels for iron and tartrazine sensing and cell imaging. Talanta 2017, 175, 305-312. [CrossRef] [PubMed]

85. Prasannan, A.; Imae, T. One-Pot Synthesis of Fluorescent Carbon Dots from Orange Waste Peels. Ind. Eng. Chem. Res. 2013, 52, 15673-15678. [CrossRef]

86. Aji, M.P.; Susanto; Wiguna, P.A. Sulhadi Facile synthesis of luminescent carbon dots from mangosteen peel by pyrolysis method. J. Theor. Appl. Phys. 2017, 22, 119-126. [CrossRef]

87. Yadav, H.A.; Eraiah, B.; Basavaraj, R.; Nagabhushana, H.; Darshan, G.; Sharma, S.; Prasad, B.D.; Nithya, R.; Shanthi, S. Rapid synthesis of C-dot@TiO2 core-shell composite labeling agent: Probing of complex fingerprints recovery in fresh water. J. Alloy Compd. 2018, 742, 1006-1018. [CrossRef]

88. Vikneswaran, R.; Ramesh, S.; Yahya, R. Green synthesized carbon nanodots as a fluorescent probe for selective and sensitive detection of iron(III) ions. Mater. Lett. 2014, 136, 179-182. [CrossRef]

89. Jadhav, P.; Sonne, M.; Kadam, A.; Patil, S.; Dahigaonkar, K.; Oberoi, J.K. Formulation of cost effective alternative bacterial culture media using fruit and vegetables waste. Int. J. Curr. Res. Rev. 2018, 10, 6-15.

90. Basu, S.; Bose, C.; Ojha, N.; Das, N.; Das, J.; Pal, M.; Khurana, S. Evolution of bacterial and fungal growth media. Bioinformation 2015, 11, 182-184. [CrossRef]

91. Deivanayaki, M.; Iruthayaraj, A.P. Alternative vegetable nutrient source for microbial growth. Inter. J. Biosci. 2012, 2, 47-51.

92. Wasas, A.D.; Huebner, R.E.; Klugman, K.P. Use of dorset egg medium for maintenance and transport of Neisseria meningitides and Haemophilus influenzae Type b. J. Clin. Microbiol. 1999, 37, 2045-2046. [CrossRef]

93. Tijani, I.D.R.; Jamal, P.; Alam, M.; Mirghani, M. Optimization of cassava peel medium to an enriched animal feed by the white rot fungi Panus tigrinus M609RQY. Int. Food Res. J. 2012, 19, 427-432. 
94. Jamal, P.; Saheed, O.K.; Kari, M.I.A.; Alam, Z.; Muyibi, S.A. Cellulolytic Fruits Wastes: A Potential Support for Enzyme Assisted Protein Production. J. Boil. Sci. 2013, 13, 379-385. [CrossRef]

95. Kahraman, S.; Gurdal, I.H. Effect of synthetic and natural culture media on laccase production by white rot fungi. Bioresour. Technol. 2002, 82, 215-217. [CrossRef]

96. Milala, M.; Shugaba, A.; Gidado, A.; Ene, A.; Wafar, J. Studies on the use of agricultural wastes for cellulase enzyme production by Aspergillus niger. Res. J. Agric. Biol. Sci. 2005, 1, 325-328.

97. Putri, C.H.; Janica, L.; Jannah, M.; Ariana, P.P. Utilization of dragon fruit peel waste as microbial growth media. In Proceedings of the 10th CISAK, Daejeon, Korea, July 2017; pp. 91-95.

98. Kindo, A.; Tupaki-Sreepurna, A.; Yuvaraj, M. Banana peel culture as an indigenous medium for easy identification of late-sporulation human fungal pathogens. Indian J. Med. Microbiol. 2016, 34, 457. [CrossRef] [PubMed]

99. Hasanin, M.; Hashem, A.H. Eco-friendly, economic fungal universal medium from watermelon peel waste. J. Microbiol. Methods 2020, 168, 105802. [CrossRef]

100. Carota, E.; Petruccioli, M.; D’Annibale, A.; Gallo, A.M.; Crognale, S. Orange peel waste-based liquid medium for biodiesel production by oleaginous yeasts. Appl. Microbiol. Biotechnol. 2020, 104, 4617-4628. [CrossRef]

101. Verma, N.; Kumar, V.; Bansal, M. Utility of Luffa cylindrica and Litchi chinensis peel, an agricultural waste biomass in cellulase production by Trichoderma reesei under solid state cultivation. Biocatal. Agric. Biotechnol. 2018, 16, 483-492. [CrossRef]

102. Verma, N.; Bansal, M.C.; Kumar, V. Pea peel waste: A lignocellulosic waste and its utility in cellulase production by Trichoderma reesei under solid state cultivation. Bioresources 2011, 6, 1505-1519.

103. Kadam, A.; Patil, S.; Sonne, M.; Dahigaonkar, K.; Oberoi, J.K.; Jadhav, P. Cost effective alternative fungal culture media formulation using fruit and vegetables waste. Int. J. Curr. Res. 2017, 9, 56887-56893.

104. Bruno, G.; Mike, P.; Christelle, B.; Goodspeed, K. Biochar is carbon negative. Nature Geosci. 2009 , $2,2$. [CrossRef]

105. Oh, J.-I.; Lee, J.; Lee, T.; Ok, Y.S.; Lee, S.-R.; Kwon, E.E. Strategic CO 2 utilization for shifting carbon distribution from pyrolytic oil to syngas in pyrolysis of food waste. J. CO2 Util. 2017, 20, 150-155. [CrossRef]

106. Carmona-Cabello, M.; Garcia, I.L.; Leiva-Candia, D.; Dorado, M.P. Valorization of food waste based on its composition through the concept of biorefinery. Curr. Opin. Green Sustain. Chem. 2018, 14, 67-79. [CrossRef]

107. Liu, Z.; Zhang, F.-S. Removal of lead from water using biochars prepared from hydrothermal liquefaction of biomass. J. Hazard Mater. 2009, 167, 933-939. [CrossRef] [PubMed]

108. Inyang, M.; Gao, B.; Yao, Y.; Xue, Y.; Zimmerman, A.R.; Pullammanappallil, P.; Cao, X. Removal of heavy metals from aqueous solution by biochars derived from anaerobically digested biomass. Bioresour. Technol. 2012, 110, 50-56. [CrossRef] [PubMed]

109. Xu, X.; Cao, X.; Zhao, L. Comparison of rice husk- and dairy manure-derived biochars for simultaneously removing heavy metals from aqueous solutions: Role of mineral components in biochars. Chemosphere 2013, 92, 955-961. [CrossRef] [PubMed]

110. Cao, X.; Ma, L.; Gao, B.; Harris, W. Dairy-manure derived biochar effectively sorbs lead and atrazine. Environ. Sci. Technol. 2009, 43, 3285-3291. [CrossRef] [PubMed]

111. Yao, Y.; Gao, B.; Inyang, M.; Zimmerman, A.R.; Cao, X.; Pullammanappallil, P.; Yang, L. Biochar derived from anaerobically digested sugar beet tailings: Characterization and phosphate removal potential. Bioresour. Technol. 2011, 102, 6273-6278. [CrossRef] [PubMed]

112. Lam, S.S.; Liew, R.K.; Cheng, C.-K.; Rasit, N.; Ooi, C.K.; Ma, N.L.; Ng, J.-H.; Lam, W.H.; Chong, C.T.; Chase, H.A. Pyrolysis production of fruit peel biochar for potential use in treatment of palm oil mill effluent. J. Environ. Manag. 2018, 213, 400-408. [CrossRef] [PubMed]

113. Zhang, B.; Wu, Y.; Cha, L. Removal of methyl orange dye using activated biochar derived from pomelo peel wastes: Performance, isotherm, and kinetic studies. J. Dispers. Sci. Technol. 2019, 41, 125-136. [CrossRef]

114. Wang, C.; Gu, L.; Liu, X.; Zhang, X.; Cao, L.; Hu, X. Sorption behavior of Cr(VI) on pineapple-peel-derived biochar and the influence of coexisting pyrene. Int. Biodeterior. Biodegradation 2016, 111, 78-84. [CrossRef]

115. Fu, B.; Ge, C.; Yue, L.; Luo, J.; Feng, D.; Deng, H.; Yu, H. Characterization of Biochar Derived from Pineapple Peel Waste and Its Application for Sorption of Oxytetracycline from Aqueous Solution. Bioresouces 2016, 11, 9017-9035. [CrossRef] 
116. Hu, X.; Zhang, X.; Ngo, H.H.; Guo, W.; Wen, H.; Li, C.; Zhang, Y.; Ma, C. Comparison study on the ammonium adsorption of the biochars derived from different kinds of fruit peel. Sci. Total Environ. 2020, 707, 135544. [CrossRef] [PubMed]

117. Wu, Y.; Cha, L.; Fane, Y.; Fang, P.; Ming, Z.; Sha, H. Activated Biochar Prepared by Pomelo Peel Using $\mathrm{H}_{3} \mathrm{PO}_{4}$ for the Adsorption of Hexavalent Chromium: Performance and Mechanism. Water Air Soil Pollut. 2017, 228, 405. [CrossRef]

118. Wu, J.; Yang, J.; Feng, P.; Huang, G.; Xu, C.; Lin, B. High-efficiency removal of dyes from wastewater by fully recycling litchi peel biochar. Chemosphere 2020, 246, 125734. [CrossRef] [PubMed]

119. Selvanathan, M.; Yann, K.T.; Chung, C.H.; Selvarajoo, A.; Arumugasamy, S.K.; Sethu, V. Adsorption of copper(II) ion from aqueous solution using biochar derived from rambutan (Nephelium lappaceum) peel: Feedforward neural network modelling study. Water Air Soil Pollut. 2017. [CrossRef]

120. Cao, Q.; Huang, Z.; Liu, S.; Wu, Y. Potential of Punica granatum biochar to adsorb Cu(II) in soil. Sci. Rep. 2019. [CrossRef]

121. Shakya, A.; Núñez-Delgado, A.; Agarwal, T. Biochar synthesis from sweet lime peel for hexavalent chromium remediation from aqueous solution. J. Environ. Manag. 2019. [CrossRef]

122. Sun, Y.; Yang, G.; Zhang, L.; Sun, Z. Preparation of high performance H 2 S removal biochar by direct fluidized bed carbonization using potato peel waste. Process. Saf. Environ. Prot. 2017, 107, 281-288. [CrossRef]

123. Niazi, N.K.; Murtaza, B.; Bibi, I.; Shahid, M.; White, J.; Nawaz, M.; Bashir, S.; Shakoor, M.; Choppala, G.; Murtaza, G.; et al. Removal and Recovery of Metals by Biosorbents and Biochars Derived From Biowastes. In Environmental Materials and Waste; Elsevier BV: Amsterdam, The Netherlands, 2016; pp. 149-177.

124. Vijayaraghavan, K.; Yun, Y.-S. Bacterial biosorbents and biosorption. Biotechnol. Adv. 2008, 26, $266-291$. [CrossRef]

125. Wang, J.; Chen, C. Biosorbents for heavy metals removal and their future. Biotechnol. Adv. 2009, 27, $195-226$. [CrossRef]

126. Park, N.; Yun, Y.-S.; Park, J.M. The past, present, and future trends of biosorption. Biotechnol. Bioprocess Eng. 2010, 15, 86-102. [CrossRef]

127. Abdi, O.; Kazemi, M. A review study of biosorption of heavy metals and comparison between different biosorbents. J. Mater. Environ. Sci. 2015, 6, 1386-1399.

128. Hameed, B.; Ahmad, A. Batch adsorption of methylene blue from aqueous solution by garlic peel, an agricultural waste biomass. J. Hazard. Mater. 2009, 164, 870-875. [CrossRef] [PubMed]

129. Krishni, R.; Foo, K.Y.; Hameed, B. Food cannery effluent, pineapple peel as an effective low-cost biosorbent for removing cationic dye from aqueous solutions. Desalination Water Treat. 2013, 52, 6096-6103. [CrossRef]

130. Shakoor, S.; Nasar, A. Adsorptive treatment of hazardous methylene blue dye from artificially contaminated water using cucumis sativus peel waste as a low-cost adsorbent. Groundw. Sustain. Dev. 2017, 5, 152-159. [CrossRef]

131. Jawad, A.H.; Kadhum, A.M.; Ngoh, Y.S. Applicability of dragon fruit (Hylocereus polyrhizus) peels as low-cost biosorbent for adsorption of methylene blue from aqueous solution: Kinetics, equilibrium and thermodynamics studies. DESALINATION Water Treat. 2018, 109, 231-240. [CrossRef]

132. Romero-Cano, L.A.; González-Gutiérrez, L.V.; A Baldenegro-Pérez, L.; Carrasco-Marin, F. Grapefruit peels as biosorbent: Characterization and use in batch and fixed bed column for $\mathrm{Cu}(\mathrm{II})$ uptake from wastewater. J. Chem. Technol. Biotechnol. 2017, 92, 1650-1658. [CrossRef]

133. Ibisi, N.E.; Asoluka, C.A. Use of agro-waste (Musa paradisiaca peels) as a sustainable biosorbent for toxic metal ions removal from contaminated water. Chem. Int. 2018, 4, 52-59.

134. Lam, Y.F.; Lee, L.Y.; Chua, S.J.; Lim, S.S.; Gan, S. Insights into the equilibrium, kinetic and thermodynamics of nickel removal by environmental friendly Lansium domesticum peel biosorbent. Ecotoxicol. Environ. Saf. 2016, 127, 61-70. [CrossRef]

135. Pavan, F.A.; Mazzocato, A.C.; Jacques, R.A.; Dias, S.L.P. Ponkan peel: A potential biosorbent for removal of $\mathrm{Pb}$ (II) ions from aqueous solution. Biochem. Eng. J. 2008, 40, 357-362. [CrossRef]

136. Mohammed, R.; Chong, M.F. Treatment and decolorization of biologically treated Palm Oil Mill Effluent (POME) using banana peel as novel biosorbent. J. Environ. Manag. 2014, 132, 237-249. [CrossRef] [PubMed]

137. Pavan, F.A.; Lima, I.S.; Lima, E.C.; Airoldi, C.; Gushikem, Y. Use of Ponkan mandarin peels as biosorbent for toxic metals uptake from aqueous solutions. J. Hazard. Mater. 2006, 137, 527-533. [CrossRef] [PubMed] 
138. Singh, S.; Parveen, N.; Gupta, H. Adsorptive decontamination of rhodamine-B from water using banana peel powder: A biosorbent. Environ. Technol. Innov. 2018, 12, 189-195. [CrossRef]

139. Ahmed, D.; Abid, H.; Riaz, A. Lagenaria siceraria peel biomass as a potential biosorbent for the removal of toxic metals from industrial wastewaters. Int. J. Environ. Stud. 2018, 75, 1-11. [CrossRef]

140. Ng, H.W.; Lee, L.Y.; Chan, W.L.; Gan, S.; Chemmangattuvalappil, N.G. Luffa acutangula peel as an effective natural biosorbent for malachite green removal in aqueous media: Equilibrium, kinetic and thermodynamic investigations. DESALINATION Water Treat. 2015, 57, 1-10. [CrossRef]

141. Gill, R.; Mahmood, A.; Nazir, R. Biosorption potential and kinetic studies of vegetable waste mixture for the removal of Nickel(II). J. Mater. Cycles Waste Manag. 2013, 15, 115-121. [CrossRef]

(C) 2020 by the authors. Licensee MDPI, Basel, Switzerland. This article is an open access article distributed under the terms and conditions of the Creative Commons Attribution (CC BY) license (http://creativecommons.org/licenses/by/4.0/). 